\title{
Experimental colonic carcinogenesis
}

Colorectal cancer (CRC) is a relevant health concern because of its incidence

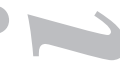
and mortality rates, as well as the expenditure it gives rise to. It is the most common gastrointestinal cancer in Western Europe and the United States, and the second leading cause of death in the Western world (1). It is the third most incident neoplasm (after prostate and lung cancer in males, and breast and lung cancer in females), with an incidence of 147,000 new cases and a mortality of 57,000 patients in the United States in 2004, according to data from the American Cancer Society (2). In our country colorectal cancer has an incidence of 20-30 cases/100,000 people/year with slight regional differences, and is responsible for $20 \%$ of malignancy-related deaths $(3,4)$.

Regarding socio-economic relevance, it should be highlighted that most studies referring to CRC-related costs have been performed in the United states and Cana$\mathrm{da}$, and primarily focus on direct costs from hospital resource utilization. CRC management in Canada is considered to amount to $4 \%$ of all economic resources devoted to the treatment of major chronic health problems, which represents some 332 million dollars per year (5). In France, with a heathcare system more similar to ours, direct costs derived from CRC diagnosis and therapy amounted to 470 million euros in 1999; when indirect costs from sick leaves, disability benefits, and loss of productivity are considered, total costs went up to 997 million euros (6).

Current strategies to improve integral treatment for CRC are based on three pillars: disease prevention, early diagnosis, and therapy optimization. Along these three major lines basic-science or experimental research and clinical investigation become intermixed, and CRC is a clear instance where translational research plays a key role in the advancement of knowledge on this disease.

Primary and secondary CRC prevention make up the field where most resources are being invested. Chemoprevention currently remains a target for both basic and applied studies in the search for drugs and optimal dosages for effective prevention; the promising role of selective COX-2 inhibitors has shrunk in the face of unexpected cardiovascular toxicity, and further searches for effective drugs in this area are needed (7). Screening protocols for CRC based on fecal occult blood testing and flexible sigmoidoscopy are shyly approached by care units, as they represent a high cost for public healthcare; hence, they are currently restricted to the population with a high risk for disease with any individual or familial origin (8).

Basic research in animal colon cancer models has been for decades a major source of knowledge for the development of disease prevention and therapy optimization. As regards prevention, all studies of chemopreventive drugs and modified diets have been previously tried in animal models. Regarding the management of $\mathrm{CRC}$, animal experiments have allowed us to deepen our insight into the carcino- 
genetic process in colonic tissue and into the modulation of this process by various experimental manipulations in animal models.

In order to advance in the understanding of experimental colonic carcinogenesis a prior step was the design of an experimental animal model that would allow results to be translated into the process of CRC development in humans. A drug-induced colon cancer model was developed during the 1980s, where animals most commonly used included rats and mice, and where most commonly used carcinogenetic drugs were 1-2-dimethylhydrazine dichloride and azoxymethane. When experimental variables include surgical manipulation rats are most commonly employed, as they lend themselves better to surgical procedures with smaller complication rates. The species most commonly used in the American continent is Rattus norvegicus, Sprague-Dawley variety, whereas the Wistar variety is most frequent in Europe, a fact seemingly resulting from tradition rather than better characteristics for experimentation. Regarding carcinogens, 1-2-dimethylhydrazine dihydrochloride is usual in Europe, whereas azoxymethane is more frequent in North America. No major difference is seemingly found between both compounds, albeit the latter is more selective for the rat's colon and is more expensive. Differences between the two continents relate to ease of acquisition from providers.

The experimental model was refined during the 1990s: carcinogen exposure times were eventually shortened, and insight into anesthesia and experimental surgery progressed, which led to a decreased postoperative mortality and a reduction in the number of animals used in experimentation. Improved overall management of experimental animals and increased understanding of statistics applied to basic biomedical research by investigators, as well as a rising interest in bioethics have all represented major advances in animal experimentation using colonic carcinogenesis models for the past two decades.

Manipulations undergone by experimental animals in experimental colonic carcinogenesis models have pursued two opposing phenomena: an increase or a decrease in the colonic carcinogenesis process. The global, common goal of all basic experimentation in this field has been and currently is the finding of a formula to modulate and interfere in the evolutionary process of colonic carcinogenesis. Research with drugs, substances or manipulated diets in animal studies requires prolonged exposure to the study substance, and usually that animals be placed in metabolic cages, which render these studies labor-intensive. Surgical procedures on the gastrointestinal tract of experimental animals have been often used to speed up the carcinogenesis process, and to optimize times in previous studies, albeit the surgical manipulation of the colon has been particularly used to investigate effects on the development of drug-induced colonic cancer.

Several studies have looked at the promoting effect of suture materials in colonic anastomoses. In the 1960s attention was drawn by reverted and everted anastomoses, as well as monoplane or biplane sutures. In 1970 Hermann (9) reported his experimental results with a new absorbable material, namely polyglycolic acid, and concluded that it had characteristics equivalent to those of non-absorbable materials, but was degraded by enzymatic mechanisms and induced milder tissue reactions. In the decade from 1980 to 1990 a special interest arises from digestive anastomoses, their materials and various modalities, and their relation to carcinogenesis in an attempt to explain anastomotic tumor recurrence. According to Rubio (10), cell proliferation as a repair mechanism in the perianastomotic area may be altered by carcinogenetic substances inducing epithelial aberrations and thus conditioning the development of malignant transformations. Williamson (11) demonstrated in 
1982 that anastomoses are prone to cancer development. In 1986 Philips and Cook (12) found a greater number of colonic tumors when anastomoses are established using steel versus reabsorbable suture. Roe (13) published a study in 1987 where anastomoses are shown to have a much higher risk for tumor development when compared to the remaining colonic mucosa, and suggested the potential chronic irritation effect of sutures as a cause. McGregor (1991) (14) reported his studies of rodents with induced carcinogenesis, and concluded that colostomy areas and surgical anastomoses are to be preferred for experimental carcinogenesis, suggesting that suture materials may act as chronic irritants exerting a co-carcinogenetic effect.

On the other hand many investigations base experimental manipulations on the need of reducing induced carcinogenesis. In 1990 Appleton (15) managed to modify carcinogenesis by using colonic defunctionalization. Studies that have modified diets by introducing supplementation or deficiencies in various substances (particulary antioxidizing vitamins and trace elements) in order to inhibit tumor development are many $(16,17)$. During the last decade most studies of this sort employed drugs in an attempt to inhibit or slow down selected enzymes that may contribute to neoangiogenesis processes, thus delaying growth from contact inhibition or apoptosis itself $(18,19)$. In this issue of Revista Española de Enfermedades Digestivas Pérez-Holanda (20) and colleagues report the results of an experimental study that clearly documents how colonic defunctionalization may alter induced carcinogenesis. The absence of feces within the colonic frame of rats undergoing an ileorectal bypass resulted in the development of induced colonic tumors that were smaller, better differentiated, and less invasive.

Finally, it should be highlighted that the gates to new experimental models are wide open. These new models will have to comply as much as possible with bioethical principles regarding animal experimentation, and particularly with Russell and Burch 3Rs principle: a) replacement by in vitro models; b) reduced numbers of animals used; and c) refinement of both surgical techniques and undesirable effects of drugs under study. All this within the new legal framework on animal experimentation (Royal Decree 1201/2005, October 10; BOE No. 252, October 21, 2005), which clearly states that all experiments should be under the tutelage of bioethical committees in research sites, and establishes minimal training requirements for those conducting or performing such experiments.

\section{J. F. Noguera Aguilar and A. Gamundí Gamundí ${ }^{1}$}

Service of General Surgery and Digestive Diseases. Hospital Son Llàtzer.

${ }^{1}$ Department of Animal Physiology. Universitat Illes Balears. IUNICS. Balearis Islands, Spain

\section{REFERENCES}

1. Arnaud JP, Scholegel M, Ollier JC, Adloff M. Colorectal cancer in patients over 80 years of age. Dis Colon Rectum 1991; 34 (10): 896-8.

2. American Cancer Society 2004. Cancer Facts \& Figures. Atlanta, Georgia; 2004.

3. García JC, Cugat E, Angás J, González FJ, Reverter JC, Lacy AM, et al. Cáncer colorectal: resultados de un protocolo de seguimiento. Cir Esp 1993; 53 (6): 430-3.

4. Domínguez Iglesias F, Riera Velasco JR, Junco Petrement P, Tojo Ramallo P, Díaz-Faes Cervero M. Effect of overexpression of P53 protein in colorectal carcinoma on short-term prognosis. Rev Esp Enferm Dig $1994 ; 86$ (5): 796-802. 
5. O’Brien BD, Brown MG, Kephart G. Estimation o hospital costs for colorectal cancer in Nova Scotia. Can J Gastroenterol 2001; 15: 43-7.

6. Selke B, Durand I, Marissal JP, Chevalier D, Lebrun T. Coût du cancer colrectal en France en 1999. Gastroenterol Clin Biol 2003; 27: 22-7.

7. Plaza A, Noguera JF, Morón JM, Ortiz E. Quimioprevención del cáncer colorrectal con inhibidores de la ciclo-oxigenasa-2. Aten Farm 2003; 5: 33-44.

8. Ramsey SD, Mandelson MT, Berry K, Etzioni R, Harrison R. Cancer-attributable costs of diagnosis and care for persons with screen-detected versus symptom-detected colorectal cancer. Gastroenterology 2003; 125 : 1645-50.

9. Herrmann JB, Kelly RJ, Higgins GA. Polyglycolic acid sutures. Laboratory and clinical evaluation of a new absorbable suture material. Arch Surg 1970; 100 (4): 486-90.

10. Rubio CA, Nylander G. Surgical resection of the rat colon: effects on carcinogenesis by 1-2 Dimethylhydrazine. JNCI 1982; 68 (5): 813-5.

11. Williamson RC, Davies PW, Bristol JB, Wells M. Intestinal adaptation and experimental carcinogenesis after partial colectomy. Increased tumour yields are confined to the anastomosis. Gut 1982; 23 (4): 316-25.

12. Phillips RKS, Cook HT. Effect of steel wire sutures on the incidence of chemically induced rodent colonic tumors. Br J Surg 1986; 73: 671-4.

13. Roe R, Fermor B, Williamson RC. Proliferative instability and experimental carcinogenesis at colonic anastomoses. Gut 1987; 28: 808-15.

14. McGregor JR, Galloway DJ, Jarret F, Brown IL, George WD. Anastomotic suture matherials and experimental colorectal carcinogenesis. Dis Colon Rectum 1991; 34: 987-92.

15. Appleton GV, Davies PW, Williamson RC. Effect of defunction on cytokinetics and cancer at colonic suture lines. Br J Surg 1990; 77 (7): 768-72.

16. Appleton GV, Davies PW, Bristol JB, Williamson RC. Inhibition of intestinal carcinogenesis by dietary supplementation with calcium. Br J Surg 1987; 74 (6): 523-5.

17. Bonithon-Kopp C, Kronborg O, Giacosa A, Rath U, Faivre J. Calcium and fibre supplementation in prevention of colorectal adenoma recurrence: A randomised intervention trial. The European Cancer Prevention Organisation Study Group. Lancet 2000; 356: 1300-6.

18. Caro-Patón Gómez A. Interleukins and colon cancer. Rev Esp Enferm Dig 2005; 97: 613-8.

19. Saif MW. Targeted agents for adjuvant therapy of colon cancer. Clin Colorectal Cancer 2006; 6: 46-51.

20. Pérez-Holanda S, Rodrigo L, Viñas Salas J, Piñol Felis C, Ildefonso C. Efecto de la desfuncionalización colónica en un modelo experimental de cáncer de colon. Rev Esp Enferm Dig 2006; 98 (9): 644-54. 